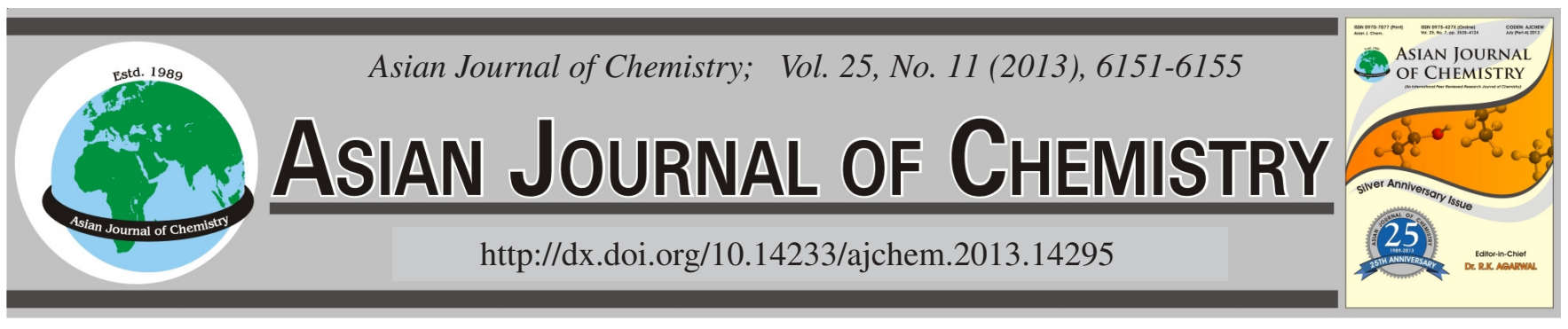

\title{
Synthesis and Phase Transition Behaviours of a Homologous Series of Pyridine Symmetrical Dimers
}

\author{
LaY-Khoon ONG ${ }^{1}$, Sie-Tiong HA ${ }^{2,3, *}$ and GuAN-YeOw YeaP ${ }^{4}$
}

${ }^{1}$ Faculty of Engineering and Science, Universiti Tunku Abdul Rahman, Jln Genting Klang, Setapak, 53300 Kuala Lumpur, Malaysia ${ }^{2}$ Faculty of Science, Universiti Tunku Abdul Rahman, Jln Universiti, Bandar Barat, 31900 Kampar, Perak, Malaysia

${ }^{3}$ Centre for Biodiversity Research, Universiti Tunku Abdul Rahman, Jln Universiti, Bandar Barat, 31900 Kampar, Perak, Malaysia

${ }^{4}$ Liquid Crystal Research Laboratory, School of Chemical Sciences, Universiti Sains Malaysia, 11800 Minden, Penang, Malaysia

*Corresponding author: E-mail: hast_utar@yahoo.com

(Received: 12 July 2012;

Accepted: 30 April 2013)

AJC-13423

\begin{abstract}
A series of symmetrical dimers bearing heterocyclic ring, $\alpha, \omega$-bis-(4-pyridine-4-methylideneaminoxy) alkanes, were prepared and all the members are differed by the alkyl spacer length $\left(\mathrm{C}_{\mathrm{n}} \mathrm{H}_{2 \mathrm{n}}\right.$, where $\left.\mathrm{n}=6,8,10,12\right)$. Differential scanning calorimetry and polarizing optical microscopy techniques were employed to study their transition temperatures and mesophase characteristics. Differential scanning calorimetry thermograms displayed direct isotropization and recrystallization during heating and cooling processes, respectively. The crystal phase texture changed to dark region (isotropic stage) without exhibiting any mesophase. Influence of molecular structure on the mesomorphic properties of symmetrical dimers was also reported.
\end{abstract}

Key Words: Dimer, Schiff base, Pyridine, Phase behaviour, Synthesis.

ᄂ - - - - - - - - - - - - - - - - - - - - - - - -

\section{INTRODUCTION}

Development of liquid crystal science and technology has led to the study of numerous new mesogens especially, thermotropic liquid crystals ${ }^{1,2}$. Most thermotropic liquid crystals are calamitic-shaped molecules having rigid core consisted of two or more aromatic rings and one or more flexible terminal chains. Schiff base is a well-known linking group used in connecting core groups. Though it provides a stepped core structure, yet it maintains molecular linearity, therefore providing better stability and enabling mesophase formation ${ }^{3,4}$. Comprehensive research on Schiff base system had been carried out ever since the discovery of 4-methoxybenzylidene-4'-butylaniline which exhibited nematic phase at room temperature ${ }^{5}$.

Over the past few decades, heterocyclic liquid crystals have received much attention due to their unique properties including a reduced packing ability (basically giving rise to lower melting points than their phenyl counterparts), a medium to strong lateral dipole, high anisotropy of the polarizability, low viscosity etc. ${ }^{6-8}$. Early results have found that the incorporation of heterocyclic ring influenced the mesomorphic properties of the calamitic molecules due to their unsaturation and/ or polarizability ${ }^{9}$. The system involving heterocyclic liquid crystals has extended from low-molar mass molecules to dimeric or oligomeric structures. The importance towards the study of dimers has developed steadily in the recent years and this could be attributed to the enormous use of dimers as model compounds to understand the importance of polymeric structure containing both semi-flexible main chain and side group ${ }^{10-12}$. In addition, liquid crystal dimers are also of important interest because these materials exhibit quite different behaviour as compared to conventional low molar mass mesogens ${ }^{13}$. These mesogens can be generally categorized into two categories: (a) symmetrical dimers in which the two mesogenic cores are identical and (b) unsymmetrical dimers which contain two nonidentical mesogenic units.

In continuation of our research on heterocyclic liquid crystals $^{14-20}$, we are prompted to introduce heterocyclic pyridine into dimer system through production of $\alpha, \omega$-bis-(4-pyridine-4methyleneaminoxy) alkanes. The phase transition and the effect of changing the spacer length of the dimers were identified, wherein these dimers differ from one another in spacer length $\left(\mathrm{CH}_{2}\right)_{\mathrm{n}}$ in which $\mathrm{n}=6,8,10$ and 12. Owing to the presence of pyridine as donor group, these compounds may also serve as mesogenic charge-transfer donors in our future studies by interacting with acceptor molecules to form binary liquid crystals ${ }^{21}$.

\section{EXPERIMENTAL}

4-Aminophenol, pyridine-4-carboxyaldehyde, 1,6dibromohexane, 1,8-dibromooctane, 1,10-dibromodecane, 
TABLE-1

PERCENTAGE YIELDS AND IR FREQUENCIES OF SYMMETRICAL DIMERS

\begin{tabular}{|c|c|c|c|c|c|c|c|}
\hline \multirow{2}{*}{ Compound } & \multirow{2}{*}{ Yield (\%) } & \multirow{2}{*}{ m.p. $\left({ }^{\circ} \mathrm{C}\right)$} & \multicolumn{5}{|c|}{$\operatorname{IR} \vee\left(\mathrm{cm}^{-1}\right)$} \\
\hline & & & $v\left(\mathrm{CH}_{3}\right)$ & $v(C=N)$ & $v(C=C)$ & $v(\mathrm{C}-\mathrm{O})$ & 1,4-disubstituted aromatic ring \\
\hline 6BP3A & 40 & 160 & 2955,2822 & 1622 & 1599 & 1253 & 835 \\
\hline 8BP3A & 46 & 152 & 2932,2859 & 1623 & 1584 & 1256 & 835 \\
\hline 10BP3A & 24 & 148 & 2939,2853 & 1622 & 1582 & 1258 & 835 \\
\hline $12 \mathrm{BP} 3 \mathrm{~A}$ & 25 & 80 & 2924,2822 & 1621 & 1587 & 1251 & 834 \\
\hline
\end{tabular}

1,10-bromododecane and potassium carbonate anhydrous were obtained commercially. The synthetic route for the title compounds are illustrated in Fig. 1.<smiles>Nc1ccc(O)cc1</smiles><smiles>Oc1ccc(/N=C/c2ccncc2)cc1</smiles><smiles>CCOc1ccc(/N=C/c2ccncc2)cc1</smiles>

Fig. 1. Synthetic route of symmetrical dimers, nBP4A

Electron ionization mass spectrum was recorded by a Finnigan MAT95XL-T mass spectrometer operating at $70 \mathrm{eV}$ ionizing energy. FT-IR spectra were acquired on Perkin Elmer 2000-FTIR spectrophotometer in the frequency range of 4000$400 \mathrm{~cm}^{-1}$ with samples prepared as $\mathrm{KBr}$ pellets. NMR spectra were recorded in $\mathrm{CDCl}_{3}$ by utilizing JEOL $400 \mathrm{MHz}$ NMR Spectrometer with TMS as internal standard. The phase transition temperatures were measured by Mettler Toledo DSC 823 differential scanning calorimeter at a scanning rate of $10{ }^{\circ} \mathrm{C} /$ min. Liquid crystalline properties were investigated using a Carl Zeiss polarizing optical microscope attached to a Linkam Hotstage.

Synthesis of $\alpha, \omega$-bis-(4-pyridine-4-methylideneaminoxy) alkanes, nBP4A: Schiff base intermediate, 4-[(pyridin4-ylmethylene)amino]phenol, $\mathrm{P} 4 \mathrm{OH}$ was obtained through step 1 (Fig. 1) according to previously reported method ${ }^{17}$. Then, $\mathrm{P} 4 \mathrm{OH}$ (2 mmol) dissolved in a minimum amount of DMF was transferred into acetone solution $(30 \mathrm{~mL})$ of dibromoalkane $(1 \mathrm{mmol})$ and anhydrous potassium carbonate $(1 \mathrm{mmol})$. The resulted mixture was stirred and heated under reflux for $24 \mathrm{~h}$. The acetone was removed via evaporation at room temperature. The final products, nBP4A were recrystallized by ethanol until constant transition temperature is obtained.
The IR, NMR $\left({ }^{1} \mathrm{H}\right.$ and $\left.{ }^{13} \mathrm{C}\right)$ and mass spectral data of the representative compound, $8 \mathrm{BP} 4 \mathrm{~A}$ are summarized as below. 8BP4A: EI-MS m/z (rel. int. \%): 506 (100) [M] ${ }^{+}, 198$ (65); IR $\left(\mathrm{KBr}, v_{\max }, \mathrm{cm}^{-1}\right): 2932,2859(\mathrm{C}-\mathrm{H}$ aliphatic), $1623(\mathrm{C}=\mathrm{N})$, $1584(\mathrm{C}=\mathrm{C}), 1256(\mathrm{C}-\mathrm{O}) ;{ }^{1} \mathrm{H} \mathrm{NMR}\left(400 \mathrm{MHz}, \mathrm{CDCl}_{3}, \delta \mathrm{ppm}\right)$ : 1.41-1.43 $\left\{\mathrm{m}, 8 \mathrm{H}, 2 \mathrm{x}-\mathrm{O}\left(\mathrm{CH}_{2}\right)_{2}\left(\mathrm{CH}_{2}\right)_{2}\right\}, 1.78-1.85\{\mathrm{p}, 4 \mathrm{H}, 2$ $\left.\mathrm{x}-\mathrm{O}\left(\mathrm{CH}_{2}\right)\left(\mathrm{C}_{2}\right)\left(\mathrm{CH}_{2}\right)_{2}\right\}, 4.0\left(\mathrm{t}, 4 \mathrm{H}, 2 \mathrm{x}-\mathrm{OCH}_{2}\right), 6.95(\mathrm{~d}, 4 \mathrm{H}$, Ar-H), 7.27 (d, 4H, Ar-H), 7.74 (d, 4H, pyridine protons), 8.48 $(\mathrm{s}, 2 \mathrm{H}, \mathrm{CH}=\mathrm{N}), 8.74(\mathrm{~d}, 4 \mathrm{H}$, pyridine protons $) ;{ }^{13} \mathrm{C} \mathrm{NMR}(100$ $\left.\mathrm{MHz}, \mathrm{CDCl}_{3} \delta \mathrm{ppm}\right): 26.00,29.30,30.95$ for $\left\{-\left(\mathrm{CH}_{2}\right)_{3}\left(\mathrm{CH}_{2}\right) \mathrm{O}\right\}$, 68.24 for $\left\{-\left(\mathrm{CH}_{2}\right) \mathrm{O}\right\}, 115.05,122.09,122.60,143.15,143.38$, $150.49,155.21$ for aromatic and pyridine carbons, 158.78 $(\mathrm{CH}=\mathrm{N})$.

\section{RESULTS AND DISCUSSION}

The percentage yields and selected IR data are tabulated in Table-1. The purity of the products, $\mathrm{nBP} 4 \mathrm{~A}$ (where $\mathrm{n}=12$, $14,16,18)$ was analyzed by TLC on silica gel plates and was chromatographically pure, as indicated by a single spot. $R_{f}$ values for two effluents system for all compounds were provided in Table-2. The phase transition temperatures and their associated enthalpy changes obtained from differential scanning calorimeter analysis over heating and cooling cycles are tabulated in Table-3.

\begin{tabular}{ccc}
\multicolumn{3}{c}{ TABLE-2 } \\
RETENTION FACTOR $\left(\mathrm{R}_{\mathrm{f}}\right)$ VALUES OF \\
SYMMETRICAL DIMERS \\
\hline Compound* & \multicolumn{2}{c}{$\mathrm{R}_{\mathrm{f}}$ value $^{* *}$} \\
\hline 6BP4A & 0.61 & ACC46 \\
8BP4A & 0.65 & 0.77 \\
10BP4A & 0.76 & 0.85 \\
12BP4A & 0.73 & 0.85 \\
\hline Single spot detected in TLC analysis; ${ }^{* * E A C 37 ~=~ E t h y l ~ a c e t a t e: ~}$ \\
Chloroform (3:7); ACC46 = Acetone: Chloroform (4:6)
\end{tabular}

TABLE-3

TRANSITION TEMPERATURES, ENTHALPY CHANGES AND PHASE TRANSITIONS OF SYMMETRICAL DIMERS

\begin{tabular}{|c|c|c|}
\hline \multirow{2}{*}{ Compound } & \multicolumn{2}{|c|}{ Transition temperatures, ${ }^{\circ} \mathrm{C}\left(\Delta \mathrm{H}, \mathrm{kJ} \mathrm{mol}^{-1}\right)$} \\
\hline & Heating & Cooling \\
\hline 6BP4A & Cr $159.2(65.3) \mathrm{I}$ & Cr 156.9 (65.5) I \\
\hline 8BP4A & Cr $152.0(70.9) \mathrm{I}$ & Cr 138.2 (69.2) I \\
\hline 10BP4A & Cr 148.1 (70.9) I & Cr 136.5 (69.4) I \\
\hline 12BP4A & $\mathrm{Cr} 79.2(50.2) \mathrm{I}$ & $\mathrm{Cr} 60.2(51.4) \mathrm{I}$ \\
\hline
\end{tabular}

EI mass spectrum (Fig. 2) showed the molecular ion peak at $m / z=506$ which was corres-ponding to molecular mass of $\mathrm{C}_{32} \mathrm{H}_{34} \mathrm{~N}_{4} \mathrm{O}_{4}$ suggested that $8 \mathrm{BP} 4 \mathrm{~A}$ was successfully synthesized. 


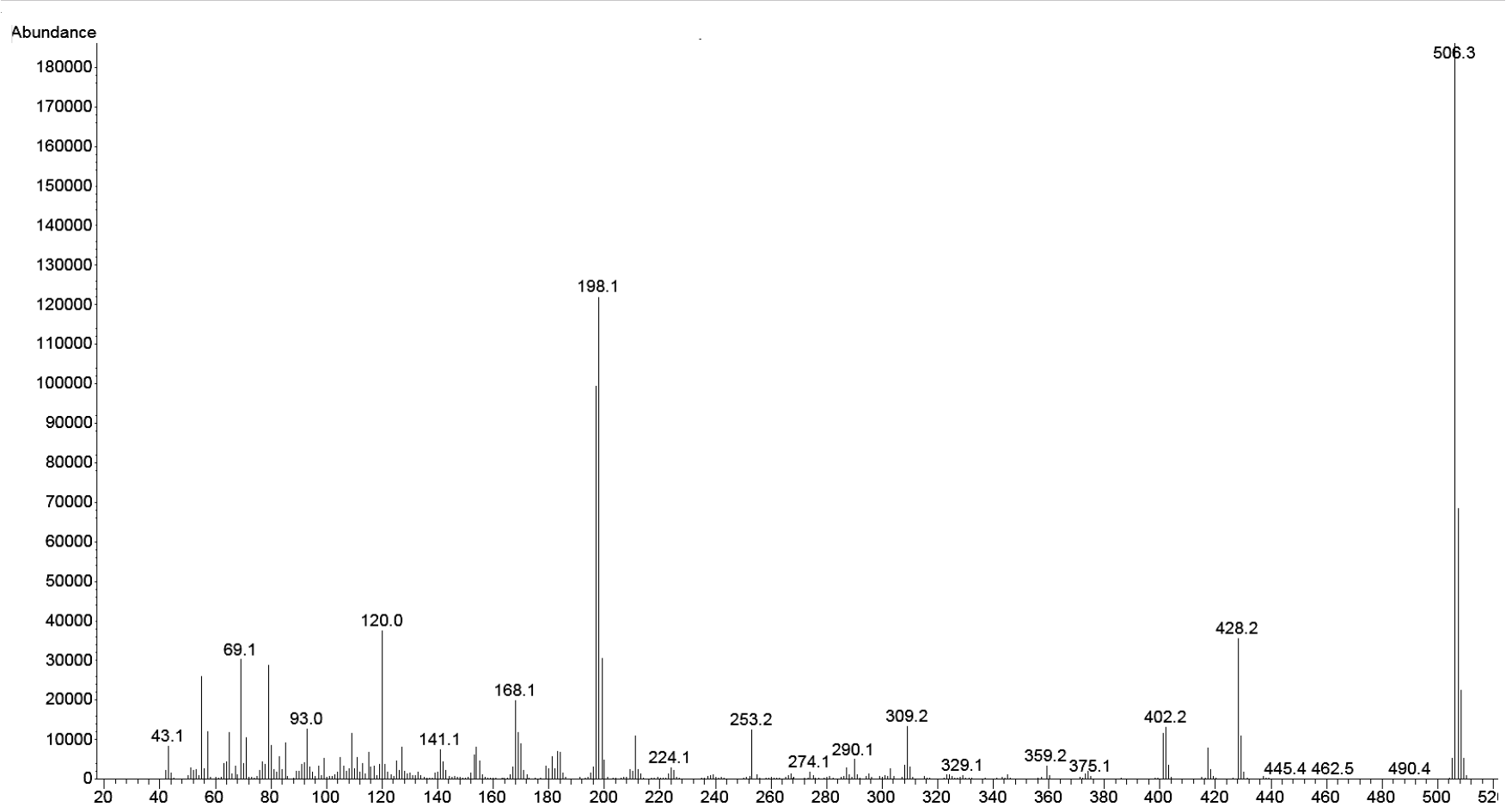

Fig. 2. EI mass spectrum of symmetrical dimer, 8BP4A

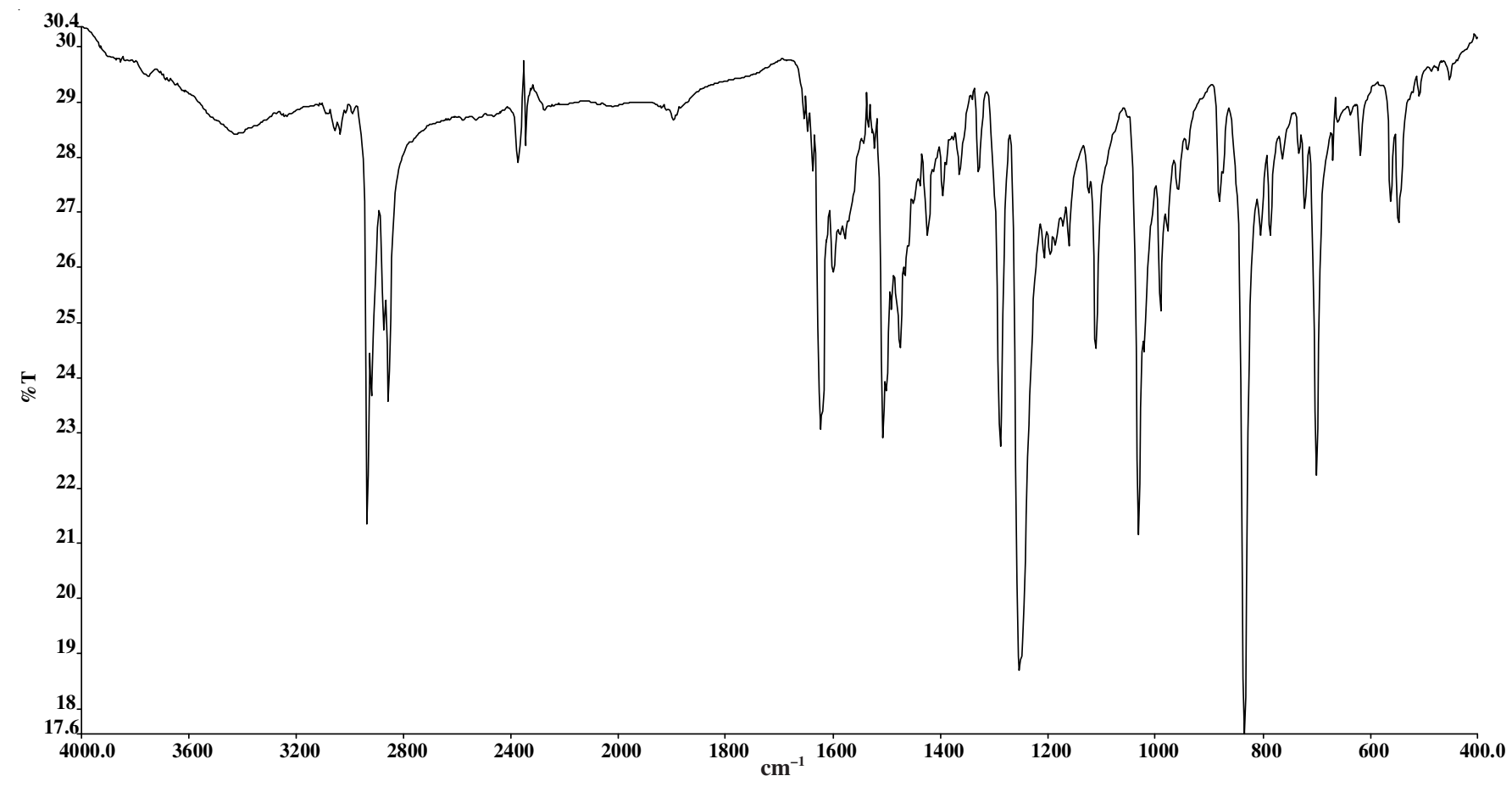

Fig. 3. FTIR spectrum of symmetrical dimer, 8BP4A

Strong absorption bands emerged at 2932 and $2859 \mathrm{~cm}^{-1}$ in FTIR spectrum of 8BP4A (Fig. 3) confirmed the presence of aliphatic C-H in alkyl chain. A sharp band at $1256 \mathrm{~cm}^{-1}$ can be ascribed to $\mathrm{C}-\mathrm{O}$ bonds of aromatic ether linking group. Absorption band appeared at $1623 \mathrm{~cm}^{-1}$ designates for $\mathrm{C}=\mathrm{N}$ linking group. This value falls within the frequency range reported for Schiff base linkage ${ }^{22-24}$.

In ${ }^{1} \mathrm{H}$ NMR spectrum of $8 \mathrm{BP} 3 \mathrm{~A}$, a triplet signal observed at $\delta=4.0 \mathrm{ppm}$, is atributed to the methylene protons attached to oxygen atom $\left(-\mathrm{CH}_{2} \mathrm{O}-\right)$. The multiplet and pentet signals appeared at $\delta=1.41-1.43$ and $1.75-1.85 \mathrm{ppm}$ can be assigned to methylene protons of long alkyl chain. Two distinct doublets detected at $\delta=6.95$ and $7.27 \mathrm{ppm}$ are belonged to the resonance of four aromatic protons. A singlet peak observed at $\delta=$ $8.48 \mathrm{ppm}$ is due to proton of imine linking group ${ }^{22-24}$. Signals (doublets) attributed to the pyridine carbons were observed at $\delta=7.74$ and $8.74 \mathrm{ppm}$. The molecular structure of 8BP4A was further verified by using ${ }^{13} \mathrm{C}$ NMR spectroscopy. A peak at $\delta=68.24 \mathrm{ppm}$ is attributed to the methylene carbons attached to oxygen atom $\left(-\mathrm{CH}_{2} \mathrm{O}-\right)$. The remaining methylene carbons were resonated at $\delta=26.00,29.30$ and $30.95 \mathrm{ppm}$. Peaks at $\delta$ $=115.05-155.21 \mathrm{ppm}$ is assigned to aromatic and pyridine 
carbons. The most downfield peak at $\delta=158.78 \mathrm{ppm}$ is due to existence of azomethine carbon.

Phase transition behaviours and optical texture studies: All homologous members were non-mesogenic compounds. In the representative differential scanning calorimeter thermogram of 8BP3A (Fig. 4), it showed single endotherm and exotherm, respectively during both heating and cooling cycles. This observation indicates direct melting of the crystal phase to the isotropic liquid phase and vice versa. Under polarizing optical microscope observation, crystal changed to dark region isotropic during heating run. No liquid crystal texture was observed during cooling process. Other members, nBP4A (where $n=6,10,12$ ) showed the similar characteristics as those discussed for 8BP4A.

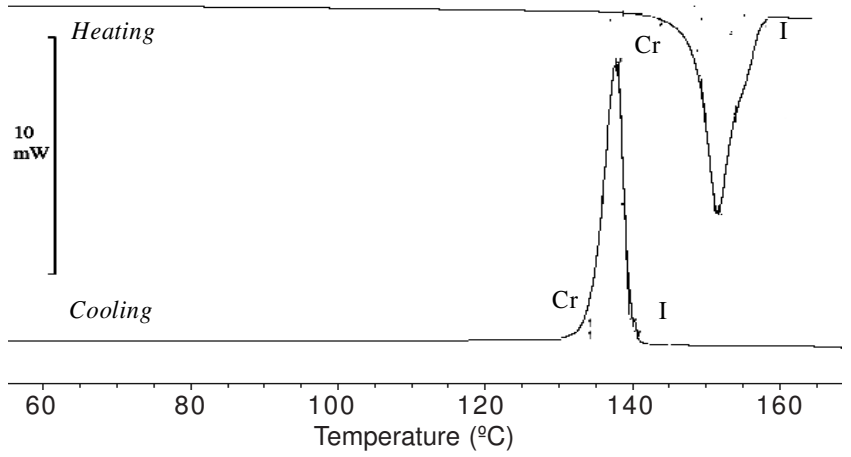

Fig. 4. DSC thermogram of symmetrical dimer, 8BP4A

Effect of alkyl chain length on transition temperatures: A further inspection on differential scanning calorimeter data also illustrates the evolution of the Cr-to-I transition with the lengthening of spacers. Fig. 5 illustrates the correlation between the transitional temperatures (Cr-to-I, I-to-Cr) with the variation in the length of alkyl spacer $\mathrm{C}_{n} \mathrm{H}_{2 n}$. This study revealed that the melting temperatures illustrate a gradual descending trend with the increase in the length of alkyl spacer from $n=6$ to $n$ $=12$. This phenomenon can be explained in terms of dilution of the core units which was influenced by the increase in the flexibility of $\operatorname{spacer}^{25,26}$. It is also important to note that upon increasing the number of carbon in $\mathrm{C}_{\mathrm{n}} \mathrm{H}_{2 n}$ units, a significant decrease of recrystallization point is observed from $n=6$ to $n$ $=12$. Again, this phenomenon can be ascribed to the flexibility of the spacer. It is also interesting to point out that there is a severe drop in the melting temperature when the alkyl space is changed $-\left(\mathrm{CH}_{2}\right)_{10^{-}}$to $-\left(\mathrm{CH}_{2}\right)_{12^{-}}$.

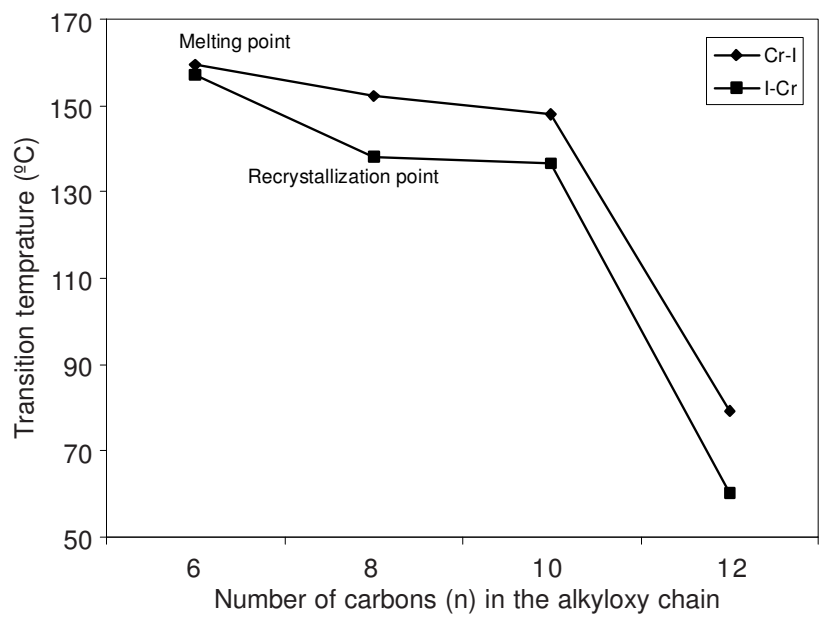

Fig. 5. Plot of transition temperatures versus number of carbons (n) in the alkyloxy chain of symmetrical dimers

Structure-mesomorphic property relationships: The mesomorphic behaviour of organic compounds is sensitive to its molecular architecture; a slight modification of molecular geometry brings about substantial change in its mesomorphic

TABLE-4

COMPARISON OF MESOMORPHIC BEHAVIOUR OF NBP4A WITH STRUCTURALLY RELATED DIMERS

Compound


behaviour $^{27}$. Investigation of these factors by experimental or theoretical means should hopefully lead to a better understanding of structure-property relationships on the synthesized compounds in liquid crystals.

In order to relate the transitional properties with the chemical constitution of molecules, the present dimers nBP4A are compared with the related liquid crystal dimers. The general molecular structure for these dimers labeled as nBAm ${ }^{27,28}$, $10 \mathrm{BABP} 10^{28}, 10 \mathrm{BABZ}^{26}$ and $\mathrm{nBABTP}^{30}$ and their phase sequence and transition temperature are shown in Table-4.

Terminal groups showed strong influence on the mesomorphic properties of a molecule (Table-4). It can be seen that the dimers with terminal alkyl chain, nBAm exhibited mesomorphic properties and dimers without terminal group, nBP4A are non-mesogens. Terminal chains bring flexibility into the molecule which is required to stabilize mesophases ${ }^{31}$. Dimers with short terminal chain, 12BA6 and 12BA7 are nematogens and longer terminal chain promotes smectic phase in $12 \mathrm{BA} 10$. As for $10 \mathrm{BABP} 10$, one side terminal chain is replaced with a polar cyano substituent but it still able to display mesophase. High rigidity of biphenyl ring in 10BABP10 also enhances its phase stability wherein its clearing temperature $\left(154.7^{\circ} \mathrm{C}\right)$ is much higher than $12 \mathrm{BP} 4 \mathrm{~A}\left(79.2^{\circ} \mathrm{C}\right)$ and nBAm $\left(131-133^{\circ} \mathrm{C}\right)$.

Presence of pyridine ring in $\mathrm{nBP} 4 \mathrm{~A}$ is not the main reasons that prevent current dimers from exhibiting mesophases. This can be evident from the case of 10BABZ and 10BATP wherein these compounds having heterocyclic benzothiazole and thiophene, respectively, are mesogens. However, it needs to complement with terminal polar chloro substituent like in the case of $10 \mathrm{BABZ}$ or having a longer molecular core through additional aromatic ring in 10BATP. Increasing the core length by inserting short unsaturated linkages (COO, ester) between phenyl and thiophene rings enhances the clearing temperature of 10BATP.

\section{Conclusion}

In this paper, we report the synthesis and characterization of new symmetrical dimers, $\alpha, \omega$-bis-(4-pyridine-4-methyleneaminoxy) alkanes. The influence of dimer spacer length, terminal (polar and alkyl chain) groups and core rings on mesomorphic properties were discussed and compared with reported dimer liquid crystals. The presence of the pyridine group renders this system to be suitable components for building charge transfer-based liquid crystals with an appropriate choice of acceptor molecules.

\section{ACKNOWLEDGEMENTS}

The authors thank Universiti Tunku Abdul Rahman and Ministry of Higher Education Malaysia for the financial support and research facilities.

\section{REFERENCES}

1. F. Yuksel, D. Atilla and V. Ahsen, Polyhedron, 26, 4551 (2007).

2. B.Y. Zhang, F.B. Meng, M. Tian and W.Q. Xiao, React. Funct. Polym., 66, 551 (2005).

3. P.J. Collings and M. Hird, Introduction to Liquid Crystals Chemistry and Physics, Taylor and Francis Ltd., London, pp. 43-176 (1998).

4. S. Singh and D.A. Dunmur, Liquid Crystals: Fundamentals. World Scientific Publishing Co. Pvt. Ltd., London, pp. 92-277 (2002).

5. H. Kelker and B. Scheurle, Angew. Chem. Int. Ed., 8, 884 (1969).

6. A. Seed, Chem. Soc. Rev., 36, 2046 (2007).

7. M.L. Parra, C.G. Saavedra, P.I. Hildago and E.Y. Elgueta, Liq. Cryst., 35, 55 (2008)

8. M.L. Parra, J. Alderete, C. Zuniga, H. Gallardo, P. Hindalgo, J. Veragara and S. Hernandez, Liq. Cryst., 28, 1659 (2001).

9. L.L. Lai, C.H. Wang, W.P. Hsien and H.C. Lin, Mol. Cryst. Liq. Cryst., 287, 177 (1996).

10. C.T. Imrie, Struct. Bonding, 95, 149 (1999).

11. C.T. Imrie, F.E. Karasz and G.S. Attard, Macromolecules, 26, 3803 (1993).

12. G.R. Luckhurst, Macromol. Symp., 96, 1 (1995).

13. C.T. Imrie and P.A. Henderson, Curr. Opin. Colloid Interf. Sci., 7, 298 (2002).

14. S.T. Ha, T.M. Koh, S.L. Lee, G.Y. Yeap, H.C. Lin and S.T. Ong, Liq. Cryst., 37, 547 (2010).

15. S.T. Ha, T.M. Koh, G.Y. Yeap, H.C. Lin, S.L. Lee, Y.F. Win and S.T. Ong, Phase Trans., 83, 195 (2010).

16. S.T. Ha, T.M. Koh, G.Y. Yeap, H.C. Lin, S.L. Lee, Y.F. Win and S.T. Ong, Mol. Cryst. Liq. Cryst., 582, 10 (2010).

17. S.T. Ha, L.K. Ong, Y.F. Win, G.Y. Yeap, N.L. Bonde and P.L. Boey, Am. J. Appl. Sci., 7, 656 (2010).

18. S.T. Ha, L.K. Ong, Y.F. Win, Y. Sivasothy, G.Y. Yeap and P.L. Boey, Aust. J. Basic Appl. Sci., 4, 1146 (2010).

19. S.T. Ha, T.M. Koh, G.Y. Yeap, H.C. Lin, P.L. Boey, Y.F. Win, S.T. Ong and L.K. Ong, Mol. Cryst. Liq. Cryst., 506, 56 (2009).

20. S.T. Ha, T.M. Koh, H.C. Lin, G.Y. Yeap, Y.F. Win, S.T. Ong, Y. Sivasothy and L.K. Ong, Liq. Cryst., 36, 917 (2009).

21. S.H. Han, H. Yoshida, Y. Nobe, M. Fujiwara, J. Kamizori, A. Kikuchi, F. Iwahori and J. Abe, J. Mol. Struct., 735-736, 375 (2005).

22. G.Y. Yeap, S.T. Ha, P.L. Boey, W.A.K. Mahmood, M.M. Ito and Y. Youhei, Mol. Cryst. Liq. Cryst., 452, 73 (2006).

23. G.Y. Yeap, S.T. Ha, P.L. Lim, P.L. Boey, M.M. Ito, S. Sanehisa and V. Vill, Mol. Cryst. Liq. Cryst., 452, 63 (2006).

24. G.Y. Yeap, S.T. Ha, P.L. Lim, P.L. Boey, M.M. Ito, S. Sanehisa and Y. Youhei, Liq. Cryst., 33, 205 (2006).

25. P.J. Collings and M. Hird, Liquid Crystal: Nature's Delicate Phase of Matter, IOP Publishing Ltd., Bristol, England (1990).

26. G.Y. Yeap, E.A. Al-Taifi, C.H. Ong, W.A.K. Mahmood, D. Takeuchi and M.M. Ito, Phase Trans., 85, 483 (2012).

27. A.K. Prajapati, N.L. Bonde, H.M. Patel, Phase Trans., 78, 507 (2005).

28. D. Bhuyan, P. Pardhasaradhi, K.N. Singh, D. Madhavi Latha, P.V. Datta Prasad, P.R. Alapati and V.G.K.M. Pisipati, World J. Condensed Matter Phys., 1, 167 (2011).

29. B. Gogoi, P.R. Alapati and A.L. Verma, Cryst. Res. Technol., 37, 1331 (2002).

30. G.Y. Yeap, T.C. Hng, D. Takeuchi, K. Osakada, W.A.K. Mahmood and M.M. Ito, Mol. Cryst. Liq. Cryst., 506, 134 (2009).

31. V. Vill, Encyclopedia of Materials: Science and Technology, Elsevier Science Ltd., p. 4545 (2001). 